\title{
Familial Ebstein's anomaly: a report of six cases in two generations associated with mild skeletal abnormalities
}

\author{
Seshadri Balaji, Nicholas R Dennis, Barry R Keeton
}

\begin{abstract}
In a family of 11 persons in three generations six had Ebstein's anomaly. Five of the six showed mild skeletal anomaliesthat is, restricted finger extension, with or without limitation of larger joints, and externally rotated little toes. Two other members of the family had the skeletal features without Ebstein's anomaly.

The findings suggest a dominantly inherited syndrome of Ebstein's anomaly and skeletal abnormalities. The four female patients were all mildly affected whereas three of the four male patients were severely affected.
\end{abstract}

There have been several reports of Ebstein's anomaly occurring in two people from the same family. ${ }^{1-3}$ Emanuel et al reviewed the published reports and examined the first degree relatives of 26 patients with Ebstein's anomaly but found no familial cases. ${ }^{4}$ Watson conducted an international cooperative study of 505 cases and found only two examples of familial incidence, both in siblings. ${ }^{5} \mathrm{We}$ report a family in which eight people in three generations had either Ebstein's anomaly or a characteristic pattern of mild skeletal anomalies or both.

\section{Case reports}

The index patient $2 \mathrm{c}$ presented in 1962 at the age of five years with an asymptomatic heart murmur that was diagnosed as Ebstein's anomaly on clinical examination; this was confirmed three years later at cardiac catheterisation. After she and her sister had had a total of five children we examined the entire family clinically and with chest $x$ ray, electrocardiogram, and echocardiogram (Doppler and colour flow mapping). Figure 1 and the table summarise the pedigree of this family. A brief summary of each member follows.

$1 a$-He was thought to have a "weak heart" when young and was not accepted for military service. At the age of 62 years he underwent aortic valve replacement for aortic stenosis. Preoperative evaluation included cardiac catheterisation; no right heart abnormalities were found. His echocardiogram was normal but the electrocardiogram showed atrial fibrillation. On examination, extension of his fingers was found to be limited (fig 2) and was accom- panied by tightening and furrowing of the palmar fascia that resembled Dupuytren's contracture. There was limited mobility of the interphalangeal joints of the thumbs, and his little toes were proximally placed and externally rotated (fig 3 ).

$1 b$-She is the wife of 1a. She was symptom free with no evidence of Ebstein's anomaly and with no skeletal abnormalities.

$2 b$ was symptom free with no clinical or echocardiographic evidence of Ebstein's anomaly. We found that extension of the little fingers was restricted at the proximal interphalangeal joints (fig 2) with tightening and furrowing of the palmar fascia as seen in 1a Elbow extension was also restricted. Her feet were high arched with overlapping of the right second and third toes, but the little toes were not externally rotated.

$2 a$-Is the non-consanguineous husband of $2 b$. He showed no evidence of Ebstein's anomaly.

$3 a$ was symptom free and had a normal electrocardiogram. Chest $x$ ray showed a cardiothoracic ratio of 0.5 and a prominent right atrial shadow on the right heart border. Echocardiography showed mild Ebstein's anomaly with small and tethered tricuspid valve septal leaflet and moderate tricuspid regurgitation. The little toes were proximally placed but there was no joint restriction.

$3 b$ was born at 33 weeks' gestation with hydrops fetalis. Echocardiography showed severe Ebstein's anomaly with no flow into the pulmonary arteries. He remained acidotic, cyanosed, poorly perfused, and anuric despite maximal support including intermittent positive pressure ventilation, dopamine and prostaglandin infusions, and paracentesis of

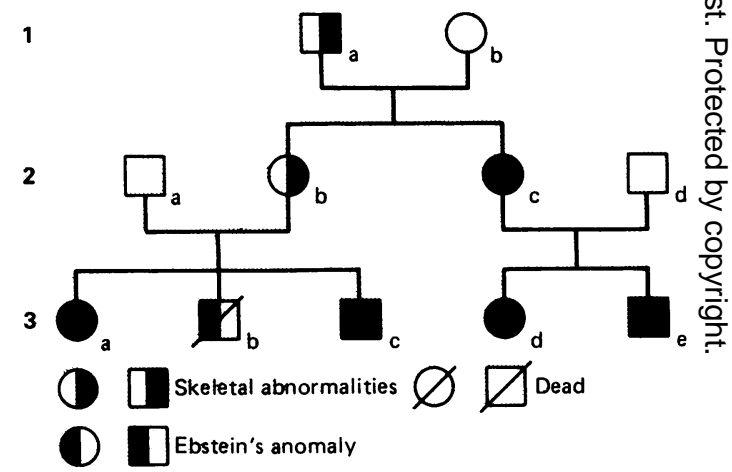

Figure 1 Pedigree of family in which some members had Ebstein's anomaly. 
Findings in the family examined

\begin{tabular}{|c|c|c|c|c|c|}
\hline Case & Age (yr) & $\begin{array}{l}\text { Ebstein's } \\
\text { anomaly }\end{array}$ & Symptoms & $\begin{array}{l}\text { Joint } \\
\text { contractures }\end{array}$ & $\begin{array}{l}\text { Toes } \\
\text { abnormal }\end{array}$ \\
\hline $1 \mathrm{a}$ & 67 & No & & + & + \\
\hline $1 \mathrm{~b}$ & 64 & No & & - & - \\
\hline $2 a$ & 31 & No & & - & - \\
\hline $2 b$ & 32 & No & & + & + \\
\hline $3 a$ & 5 & Yes & No & - & + \\
\hline $3 b$ & ND & Yes & Yes & - & - \\
\hline $3 c$ & $1 \mathrm{mnth}$ & Yes & Yes & + & + \\
\hline $2 c$ & 30 & Yes & No & + & + \\
\hline $2 d$ & 30 & No & - & - & - \\
\hline $3 \mathrm{~d}$ & 7 & Yes & No & + & + \\
\hline $3 e$ & 3 & Yes & Yes & + & + \\
\hline
\end{tabular}

ND, neonatal death.

Figure 2 Limitation of extension of proximal interphalangeal joints in $2 b$ (left) and $1 a$ (right). right ventricle, and moderate tricuspid regur- the pleural and peritoneal cavities. He died aged one day and necropsy confirmed the diagnosis. No skeletal abnormalities were noted.

$3 c$ presented in the neonatal period with cyanosis and signs of heart failure. Echocardiography showed mild Ebstein's anomaly and he improved with oxygen and diuretics. He had simian creases and limitation of extension of the metacarpophalangeal joints by palmar soft tissues, but no limitation of other joints. His little toes were proximally placed and externally rotated (fig 3 ).

$2 c$-An asymptomatic cardiac murmur was detected when she was five years old. A clinical diagnosis of Ebstein's anomaly was made which was confirmed at cardiac catheterisation when she was eight years old. She remains symptom free and experienced no cardiac problems during her pregnancies. Echocardiography showed a large right atrium, small gitation. She had restricted extension of all fingers, similar to $1 a$ and $2 b$, plus limitation of elbow extension. Her feet were high arched

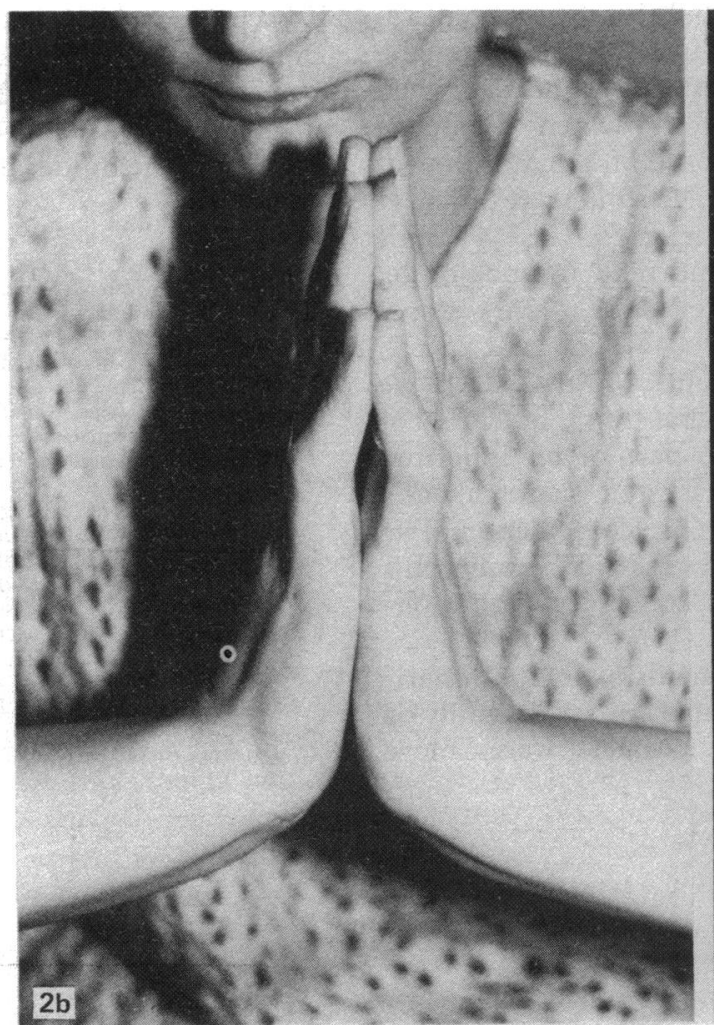

and the little toes were short and externally rotated (fig 3).

$2 d$ is the non-consanguineous husband of $2 c$, in whom all findings were normal.

$3 d$ was symptom free with no evidence of cardiac problems on clinical, $x$ ray, and electrocardiographic examination. Echocardiography showed mild Ebstein's anomaly with apical displacement of the septal leaflet of the tricuspid valve and mild tricuspid regurgitation. Finger extension was limited as in 1a and $2 \mathrm{~b}$, and ankle mobility was slightly reduced. Her little toes were externally rotated.

$3 e-\mathrm{He}$ presented as a neonate with cyanosis and cardiac failure. Echocardiography at this time showed severe Ebstein's anomaly. He remained symptomatic with shortness of breath on exertion. Echocardiography when he was three years old showed a large right atrium, small right ventricle, and moderate tricuspid stenosis and regurgitation. The mitral valve was also abnormal with mild mitral stenosis and a thickened valve that appeared to be dysplastic. Extension of knees, elbows, fingers, and hands were restricted (as in $1 \mathrm{a}$ and $2 \mathrm{~b}$ ), and also abduction of the hips. His calves were slightly wasted but no neurological abnormalities were detected. His feet were high arched and his little toes were externally rotated (fig 3 ). His thumbs were broad and short.

None of the family showed abnormalities on examination of the nervous system. There was no evidence of pre-excitation or WolffParkinson-White syndrome on the electrocardiogram.

\section{Discussion}

Familial Ebstein's anomaly is rare. Gueron et al

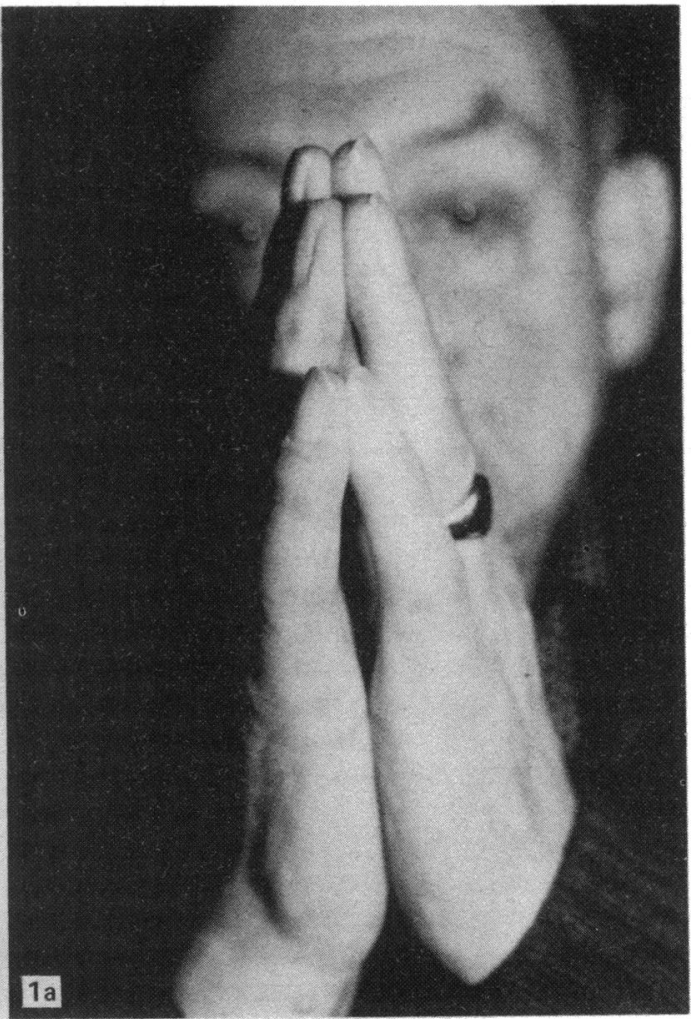


Figure 3 Proximally placed and externally rotated little toes in $3 c, 3 e$, $1 a$, and $2 c$.

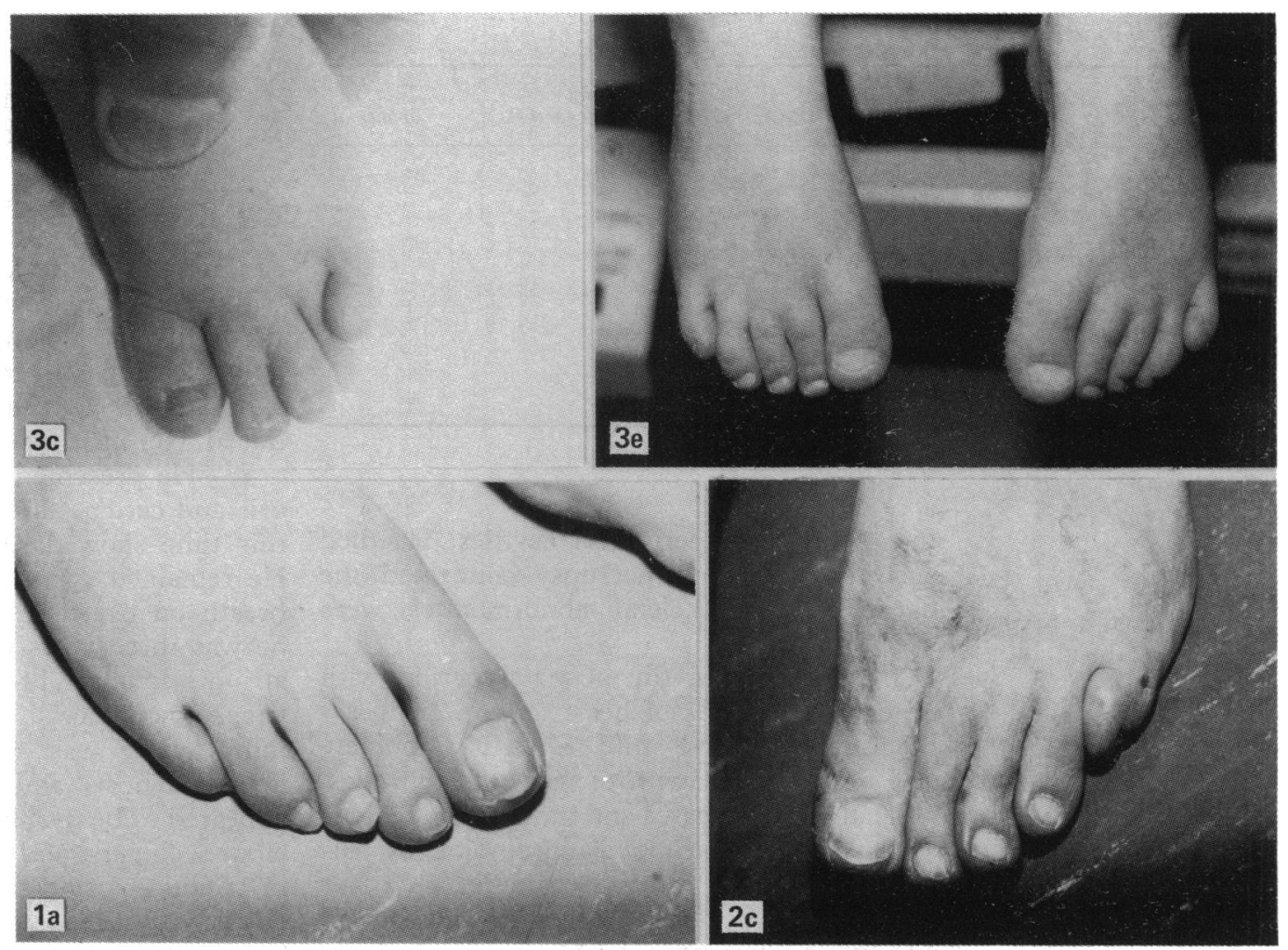

reported a 20 year old man and his sister aged 12 , who were born to second cousins, and who both died of Ebstein's anomaly. ${ }^{1}$ Donegan et al reported the condition in a boy and his maternal uncle. ${ }^{2}$ Simcha and Bonham-Carter reported two families; in one two brothers were affected and in the other a father and daughter were affected. ${ }^{3}$ Watson in a large international cooperative study of 505 cases could only find two examples of siblings with this condition. ${ }^{5}$ Our report is, therefore, to our knowledge, the largest of its kind.

Extracardiac abnormalities have been reported in association with Ebstein's anomaly, most notably by Siebert et al who described four unrelated cases in which Ebstein's anomaly occurred as part of a syndrome of multiple malformations. ${ }^{6}$ All four were different and none resembled our cases. Case 4 seems to have the OEIS syndrome (omphalocele, exstrophy, imperforate anus, and spinal defects). ${ }^{\text {? }}$

The skeletal abnormalities in the family we studied seem to be familial traits, but it is not clear whether they are part of an inherited syndrome that includes Ebstein's anomaly as a feature, or whether they are coincidental. The findings in the hands resembled Dupuytren's contracture, but were congenital and nonprogressive.

The most likely mechanism for the inheritance of Ebstein's anomaly in this family is autosomal dominance. Males were more severely affected than females. The degree of variability in the male cases makes $\mathrm{X}$-linkage unlikely, but in the absence of male to male transmission this cannot be excluded.

This family also shows that Ebstein's anomaly continues to be a poorly understood cardiac problem with a wide spectrum of clinical presentation. Watson suggested that most patients are either symptom free or have only slight symptoms. ${ }^{5}$ This may mean that the incidence of familial cases is underestimated.

There is a need for a systematic study of Ebstein's anomaly by echocardiography and Doppler techniques to determine what proportion of those who present clinically have mildly affected relatives and to define the anatomical features of the milder defects.

1 Gueron M, Hirsch M, Stern J, Cohen W, Levy MJ. Familia Ebstein's anomaly with emphasis on surgical treatment. Am J Cardiol 1966;8:105-11.

2 Donegan CC, Moore MM, Wiley TM, Hernandez FA, Green JR, Schiebler GL. Familial Ebstein's anomaly of the tricuspid valve. Am Heart J 1968;75:375-9.

3 Simcha A, Bonham-Carter RE. Ebstein's anomaly: clinical 46-9.

4 Emanuel $\mathrm{R}$, O'Brien $\mathrm{K}, \mathrm{Ng} \mathrm{R}$. Ebstein's anomaly: genetic study of 26 families. Br Heart J 1976;38:5-7.

5 Watson $\mathrm{H}$. Natural history of Ebstein's anomaly of tricuspid valve in childhood and adolescence: an international cooperative study of 505 cases. Br Heart J 1974;36:417-27.

6 Siebert JR, Barr M, Jackson JC, Benjamin DR. Ebstein's anomaly and extracardiac defects. Am J Dis Child 1989, 143:570-2.

7 Carey JC, Greenbaum B, Hall BD. The OEIS complex (omphalocele, exstrophy, imperforate anus, spinal defects). Birth Defects 1978;14(6B):253-63. study of 32 patients in childhood. Br Heart $J$ 1971;33: 